\title{
Industri 4.0 : Pengukuran Tingkat Kesiapan Industri Tekstil dengan Metode Singapore Smart Industry Readiness Index
}

\author{
Satrio Utomo ${ }^{1}$, Nugraheni Setiastuti ${ }^{2}$ \\ ${ }^{I}$ Pusat Pengkajian Industri Manufaktur,Telematika Dan Elektronika \\ ${ }^{2}$ Kedeputian Pengkajian Kebijakan Teknologi - Badan Pengkajian dan Penerapan Teknologi
}

\begin{tabular}{l} 
KEYWORDS \\
\hline industri 4.0, daya saing, inovasi, singapore \\
smart industry readiness index
\end{tabular}

\section{CORRESPONDENCE}

Phone: 081310787231

E-mail: satrioutomo2005@yahoo.com

\section{PENDAHULUAN}

Salah satu fase penting dalam perkembangan teknologi saat ini adalah munculnya revolusi industri gelombang ke-4, atau yang lebih dikenal Industrial Revolution 4.0.Istilah revolusi industri 4.0 pertama kali muncul tahun 2012, ketika pemerintah Jerman memperkenalkan strategi teknologi modern Jerman 2020 (Germany's High-Tech Strategy 2020) yang disebut dengan Industrie 4.0.Strategi tersebut diimplementasikan melalui peningkatan teknologi sektor manufaktur, penciptaan kerangka kebijakan strategis yang konsisten, serta penetapan prioritas tertentu dalam menghadapi kompetisi global.

Dari hal tersebut, kemudian muncul istilah industrial revolution 4.0.Kata 'revolusi' digunakan untuk menunjukkan perubahan yang sangat cepat dan fundamental, serta bersifat disruptive (merusak tatatan lama yang sudah ada selama bertahun-tahun).Sementara gelombang ke-4 menandakan urutan kejadian revolusi industri yang pernah ada.Industri 1.0 di mulai dengan memperkaryakan air dan kekuatan uap untuk mekanisasi

\section{A $\mathbf{B} \quad \mathbf{S} \mathbf{T} \quad \mathbf{R}$ A $\mathbf{C}$ T}

Era disrupsi teknologi saat ini, yang lebih dikenal Revolusi Industri 4.0, sudah mulai diterapkan pada berbagai bidang di setiap negara. Industri 4.0 ini ditopang oleh teknologi terkini seperti Internet of Things (IoT), Artificial Intelligence (AI), Human-Machine

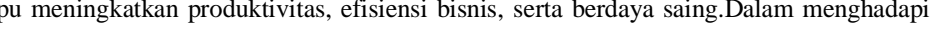
4.0' dengan mempersiapkan peta jalan (Roadmap) dan strategi dalam menyongsong industri 4.0.Terdapat 5 (lima) sektor industri prioritas, antara lain industri Makanan Dan Minuman, Tekstildan Produk Tekstil, Otomotif, Elektronik dan Kimia. Untuk itu, kajian dilakukan pada menghadi apa yang dibutuhkan untuk menuju ke level industri 4.0. Dengan mengetahui posisi tersebut, untuk peningkatan daya saing industri menuju level industri 4.0. Berdasar hasil pemetaan, diketahui bahwa tingkat kesiapan industri tekstil PT.Grand Tekstil berdasar aspek Teknologi $1,56)$, aspek Proses $(1,33)$ dan aspek Organisasi $(2,00)$ adalah sebesar 1,63; posisi pada level 1 dikategorikan sebagai New Comer.

sistem produksi. Industri 2.0, ditandai dengan pemanfaatan tenaga listrik (electricity) untuk mempermudah serta mempercepat proses produksi, distribusi, dan perdagangan. Industri 3.0 ditandai dengan adanya sistem teknologi informasi dan komputerisasi untuk menunjang otomatisasi produksi (production automation).Industri 4.0 selanjutnya hadir menggantikan industri 3.0 yang ditandai dengan cyber fisik dan kolaborasi manufaktur (Irianto, 2017).

Industri 4.0 ditandai dengan peningkatan digitalisasi manufaktur yang didorong oleh empat faktor: 1) peningkatan volume data, kekuatan komputasi, dan konektivitas; 2) munculnya analisis, kemampuan, dan kecerdasan bisnis; 3) terjadi bentuk interaksi baru antara manusia dengan mesin; dan 4) perbaikan instruksi transfer digital ke dunia fisik, seperti robotika dan 3D printing. Prinsip dasar industri 4.0 adalah penggabungan mesin, alur kerja, dan sistem, dengan menerapkan jaringan cerdas di sepanjang rantai dan proses produksi untuk mengendalikan satu sama lain secara mandiri (Muhammad, 2018). 
Era industri 4.0, sudah mulai diterapkan pada berbagai bidang di setiap negara. Pada bidang manufaktur, teknologi pendorong industri 4.0 diharapkan dapat meningkatkan efisiensi produksi, produktifitas serta daya saing dalam persaingan global. Salah satu kunci dalam pemanfaatan teknologi digital adalah konektivitas, sehingga diperlukan integrasi konektivitas. Dalam menghadapi era industri 4.0 tersebut, pada tanggal 4 April 2018, Kementerian Perindustrian telah mencanangkan Making Indonesia 4.0 dengan mempersiapkan peta jalan (roadmap) dalam menyongsong industri 4.0 di Indonesia.

Terdapat 5 (lima) sektor industri yang menjadi prioritas Indonesia dalam menyongsong industri 4.0, antara lain industri makanan dan minuman, tekstil dan produk tekstil, otomotif, elektronik dan kimia.(Kemenperin, 2018).Industri manufaktur menjadi perhatian bagi pemerintah, karena mampu mengurangi pengangguran dan menciptakan lapangan kerja.industrimanufaktur masih menjadi kontributor terbesar terhadap Produk Domestik Bruto (PDB) nasional dengan capaian 20,16 persen pada tahun 2018 (sumber : BPS. 2018).

Industri tekstil dan produk tekstil (TPT) memberikan kontribusi cukup besar terhadap pertumbuhan ekonomi, selain menciptakan lapangan kerja cukup besar, industri ini mendorong peningkatan investasi dalam dan luar negeri. Industri TPT merupakan industri padat karya yang telah berkontribusi 6,39 persen dari total PDB (Produk Domestik Bruto) tahun 2018. Oleh karena itu, sesuai Rencana Induk Pembangunan Industri Nasional (RIPIN), industri TPT termasuk industri prioritas. Tetapi secara fakta, adanya revolusi industri 4.0 membuat industri manufaktur khususnya industri tekstil sepertinya belum siap menghadapi revolusi industri 4.0 (Unido,2017).

Industri tekstil dan produk tekstil harus ditingkatkan menjadi level business as usual. Keunggulan industri tekstil dan produk tekstil diharapkan dapat meningkatkan jumlah produksi, dan didukung oleh pertumbuhan pemilikan produksi dan pendapatan. Selain itu, industri tekstil dan produk tekstil juga diharapkan dapat berkontribusi langsung pada pertumbuhan, kemandirian, kemajuan, keadilan dan kesejahteraan ekonomi di Indonesia (Riyardi, Agung dkk, 2015).

Indonesia bersama dengan China dan India, merupakan negara dengan industri TPT yang terintegrasi di Asia. Industri terintegrasi ini melibatkan industri hulu hingga hilir dalam menghasilkan produk akhir, yaitu meliputi serat dan benang, kain, hingga garmen (pakaian jadi). Indonesia menempati urutan ke-17 sebagai eksportir TPT (tekstil dan produk tekstil) dunia dengan share $1,5 \%$. Posisi Indonesia kalah bersaing dengan Bangladesh dan Vietnam (Sahat, 2016).

Saat ini masih terdapat kelemahan produksi dalam negeri untuk bersaing dengan produsen negara lain, yaitu : Weaving, Knitting, Dyeing, Finishing serta sektor penunjang seperti spinning dan serat (sumber : Kompas.com).Tantangan yang dihadapi saat ini adalah keterbatasan akses ke pasokan bahan mentah dan ketergantungan tinggi pada bahan impor.

Adanya perkembangan revolusi industri 4.0 tidak bisa dihindarkan, menjadikan pelaku usaha di sektor Tekstil dan Produk Tekstil (TPT) harus bisa melakukan transformasi untuk menghadapi era industri 4.0sebagai upaya efisiensi dan daya saing menghadapi produk negara lain. Sementara perusahaan mengenali peluang industri 4.0, namun tidak tahu di mana dan bagaimana memulainya.Untuk itu perlu ada kajian penelitian yang dapat membantu perusahaan menentukan di mana memulai dan bagaimana mengukur dan mempertahankan industri sekaligus mampu berdaya saing. Selain itu akan bermanfaat bagi pemerintah dalam mempersiapkan kebutuhan infrastruktur dan pelaku usaha terkait.

Pemilihan industri tekstil dilaksanakan di PT. Grand Textile Industry Bandung; perusahaan yang bergerak dibidang industri textile, spesialisasi memproduksi kain denim (Jeans) dan grey (chambray).Hasil produksi yang sudah siap dipasarkan dikemas dalam bentuk gulungan. Kain denim diproduksi dengan cararope dyed dan slasher dyed. Jenis produksi tersebut memiliki daerah pemasaran yang luas, namun karena proses produksi memerlukan teknologi yang cukup rumit, sehingga tidak banyak perusahaan di indonesia yang mampu memprosesnya.

Tujuan dari penelitian ini adalah :

1. Identifikasi dan penilaian tingkat teknologi industri textile menuju level industri 4.0 berdasar komponen teknologi, yaitu Teknologi, Proses, dan Organisasi;

2. Memahami konsep Metode Singapore Smart Industry Readiness Index (SmS); sebagai alat standarisasi industri 4.0 pertama kali di dunia yang diciptakan oleh pemerintah Singapura bekerja sama dengan TUV SUD, perusahaan inspeksi, sertifikasi, dan pelatihan asal Jerman serta sudah divalidasikan oleh penasehat industri dan akademisi.

Hasil penelitian berupa dokumen kajian tentang strategi industri textile sehingga mampu berdaya saing dalam dunia manufaktur menuju level industri 4.0.

\section{METODE}

Kajian permasalahan dilakukan pada salah satu sektor industri manufaktur, yaitu industri tekstildi PT Grand Textile, berlokasi di Bandung, Jawa Barat.

Penelitian dilakukan dengan menyiapkan instrumen dan wawancara dengan pihak expert (informan) serta pengamatan langsung untuk melihat bagaimana proses produksinya, bagaimana cara melakukan distribusi barang dan memasarkan ke pasar serta bagaimana proses ekspor dan impor barang. Selain itu, dikumpulkan pula informasi lainnya mengenai berbagai kondisi di perusahaan manufaktur tersebut sehingga mendapatkan masalah nyata dari hasil pengamatan secara langsung terkait dengan kesiapan menghadapi industri 4.0

Penilaian kesiapan teknologi industri menghadapi revolusi industri 4.0 menggunakan Metode Singapore Smart Industry Readiness Index (SmS).Metode $\mathrm{SmS}$ ini sudah diresmikan oleh Pemerintah Singapura sebagai sebuah standar alat ukur kesiapan industri memasuki era industri 4.0 pada bulan Oktober 2017.Standar yang dimaksud, diantaranya bagaimana mengisi peluang pasar dan mengantisipasi tren pertumbuhan, mendorong produktivitas, mengoptimalkan sumber daya secara efisien, dan mendukung standar keamanan dan kebutuhan sosial.SmS menghadirkan standar kebutuhan industri dalam menghadirkan interoperabilitas, reliabilitas, kenyamanan dan keamanan siber. 
Dengan standar tersebut diharapkan berdampak pada perusahaan dalam menumbuhkan produktivitas, mengembangkan pasar, efisiensi sumber daya dan keamanan dan kebutuhan sosial.

Indikator diidentifikasi dalam framework tersebut meliputi 3 (tiga) aspek : Teknologi, Proses, dan Organisasi. Selanjutnya 3 (tiga) aspek terbagi menjadi 8 (delapan) pilar utama, yaitu Operations, Supply Chain, Product Lifecycle, Automation, Connectivity, Intelligence, Structure \& Management, dan Talent Readiness. Dari 8 (delapan) pilar utama, diuraikan menjadi 16 (enam belas) dimensi.

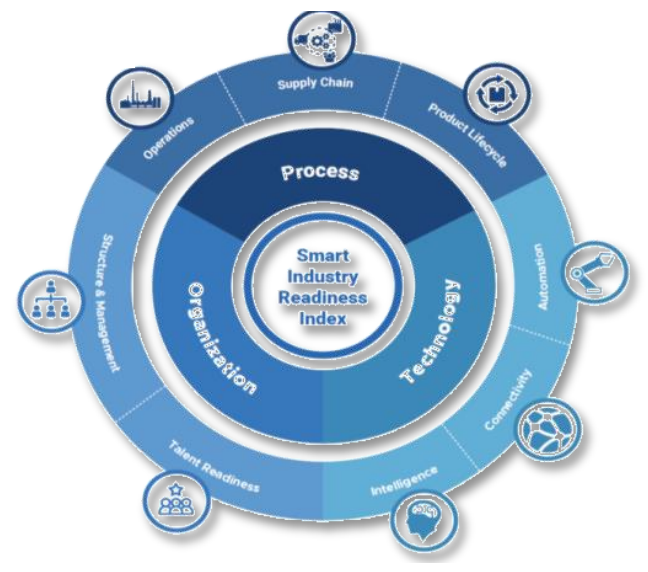

Gambar 1. Indikator dalam Framework SmS

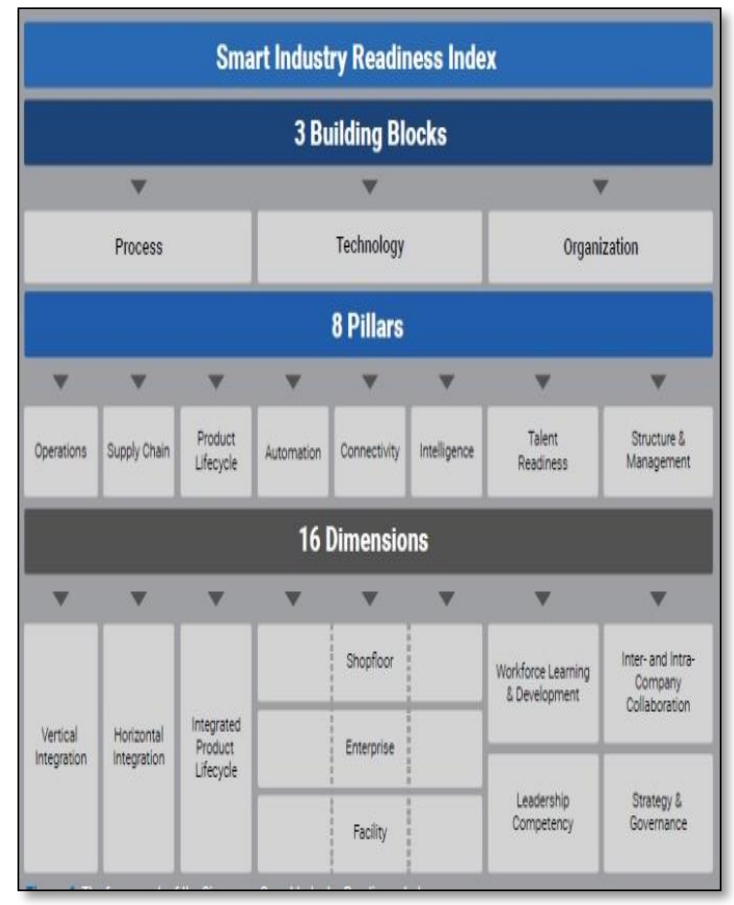

Gambar 2. Framework Singapore Smart Industry Readiness Index

Berikut 3 (tiga) aspek dalam SmS adalah :

\section{- Aspek Teknologi}

Teknologi digital baru, seperti cloud computing, machine learning, dan Internet of Things (IoT),akan menciptakan sebuah lanskap industri hyper-connected, di mana aset dan peralatan fisik diintegrasikan dengan sistem perusahaan untuk memungkinkan pertukaran dan analisis data yang konstan dan dinamis.

Aspek Teknologi dibagi menjadi 3 pilar, yaitu otomasi (automation), konektivitas (connectivity), dan kecerdasan (inteligence).

- Pilar Automation; mengatur otomatisasi perusahaan. Contoh : robot kolaboratif dan mesin cetak 3D. Terbagi atas 3 dimensi : Shop Floor Automation, Enterprise Automation, Facility Automation.

Dalam pilar Automation, menggunakan skor penilaian (0-5) : level 0 (None), level 1 (Basic), level 2 (Advanced), level 3 (Full), level 4 (Flexible), level 5 (Converged)

- Pilar Connectivity; Konektivitas membantu dalam membangun jaringan sensor. Keamanan siber juga terlindungi. Terbagi 3 Dimensi :Shop Floor Connectivity, Enterprise Connectivity, Facility Connectivity.

Dalam pilar Connectivity menggunakan skor penilaian (0-5) : level 0 (None), level 1 (Connected), level 2 (Interoperable), level 3 (Interoperable and Secure), level 4 (Real Time), level 5 (Scalable)

- Pilar Inteligence menstandarkan intelijensi perusahaan dengan mengambil data dari mesin. Seperti misalnya untuk mengurangi tingkat kesalahan mesin, meningkatkan produksi, meningkatkan efisiensi alat dan mengurangi kerusakan alat. Terbagi atas 3 dimensi : Shop Floor Intelligence, Enterprise Intelligence, Facility Intelligence. Dalam pilar Inteligence menggunakan skor penilaian (0-5) : level 0 (None), level 1 (Computerized), level 2 (Visible), level 3 (Diagnostic), level 4 (Predictive), level 5 (Adaptive)

\section{- Aspek Proses}

Pada Industri 4.0, konsep peningkatan proses telah diperluas fokusnya pada integrasi proses dalam operasi perusahaan (Operations), rantai pasok (Supply Chain),dan siklus hidup produk (Product Lifecycle).

- Pilar Operations; memberikan standar sistem dan mesin dari beragam vendor agar dapat bekerja dalam satu pengoperasian. Serta, bagaimana mengatur mengurangi konsumsi energi. Terdiri dari 1 dimensi :Vertical integration.

- Pilar Supply Chain; standar yang menangani proses dan prosedur pada operasi rantai suplai supaya menjamin keamanan dan kelangsungan bisnis. Terdiri dari 1 dimensi: Horizontal Integration.

- Pilar Product Lifecycle; Standar ini mengatur agar produk memiliki kualitas lebih baik dan stabilitas. Terdiri dari 1 dimensi :Integrated product lifecycle.

Ketiga pilar dalam aspek process tersebut menggunakan skor penilaian (0-5): level 0 (Undefined), level 1 (Defined), level 2 (Digital), level 3 (Integrated), level 4 (Automated), level 5 (Intelligent) 


\section{- Aspek Organisasi}

Terdapat 2 (dua) elemen kunci yang dapat mempengaruhi efektivitas organisasi.Yaitu orang yang terlibat dalam perusahaan (Talent Readiness), dan sistem kelembagaan (Structure\& Manajement)

- Pilar Talent Readiness;kemampuan tenaga kerja dalammendorong dan memberikan inisiatif menyongsong industri 4.0 agar dapat sukses dijalankan.Terbagi atas 2 dimensi yaitu Dimensi Workforce Learning \& Development dan Dimensi Leadership Competence.

Pada Dimensi Workforce Learning \& Development menggunakan skor penilaian (0-5) : level 0 (Informal), level 1 (Structured), level 2 (Continuous), level 3 (Integrated), level 4 (Adaptive), level 5 (ForwardLooking).

Sedangkan dimensi Leadership Competence menggunakan skor penilaian (0-5) : level 0 (Unfamiliar), level 1 (Limited Understanding), level 2 (Informed), level 3 (Semi Dependent), level 4 (Independent), level 5 (Adaptive).

- Pilar Structure\& Manajement; Struktur mempengaruhi bagaimana tim bertindak dan berinteraksi dan bagaimana inisiatif harus dilaksanakan untuk mencapai tujuan organisasi. Terbagi atas 2 dimensi yaitu Dimensi Inter and Intra Company Collaboration dan dimensi Strategy and Governance.

Dalam dimensi Inter and Intra Company Collaborationmenggunakan skor penilaian (0-5): level 0 (Informal), level 1 (Communicating), level 2 (Cooperating), level 3 (Coordinating), level 4 (Collaborating), level 5 (Integrated)

Dalam dimensi Strategy and Governancemenggunakan skor penilaian (0-5) : level 0 (None), level 1 (Formalization), level 2 (Development), level 3 (Implementation), level 4 (Scaling), level 5 (Adaptive) .

Tingkat kesiapan industri menghadapi industri 4.0 digambarkan dalam 6 level, dimulai Outsider, Beginner, Intermediate, experienced, Expert, Top performer

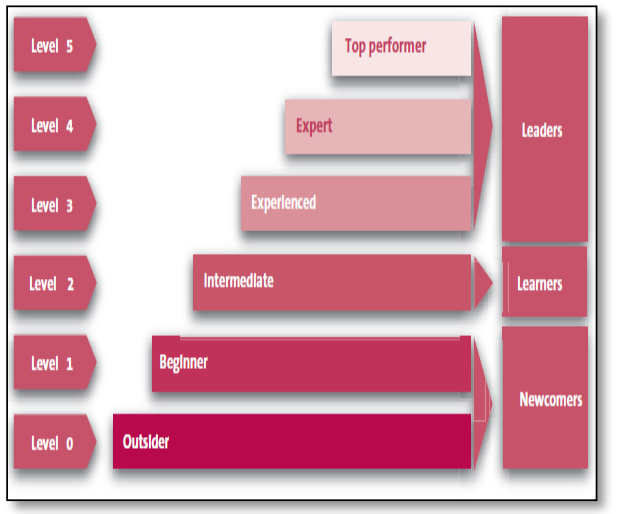

Gambar 3.Tingkat Kesiapan Industri 4.0.
Berdasar Gambar 3, Tingkat kesiapan industri 4.0 terdiri dari 6 level (Level 0-5), dan dari keenam level Kesiapan Industri 4.0 dikelompokkan 3 jenis perusahaan, yaitu:

1). New Comer (Level 0 dan 1)

2). Learners (Level 2)

3). Leaders (Level 3 keatas)

- KelompokNew Comer (level 0 dan 1); perusahaan yang belum atau sangat sedikit mengimplementasikan Industri 4.0 ;

- Kelompok Learner (level 2); perusahaan yang telah mengambil langkah pertama dalam mengimplementasikan Industri 4.0.

- Kelompok Leaders (Level 3 sampai 5); perusahaan telah mencapai sekurang-kurangnya level 3. Perusahaan dalam kelompok ini telah menerapkan Industri 4.0 secara masif pada aspek teknologi, proses, dan organisasi.

\section{HASIL DAN PEMBAHASAN}

Berdasar penilaian menggunakan Metode Singapore Smart Industry Readiness Index $(\mathrm{SmS})$ pada PT.Grand Textile adalah:

\section{- Aspek Teknologi}

- Untuk Shop Floor Automation berada di level basic, karena belum adanya shop floor control seperti posisi stok barang, kebutuhan material pada shop floor dan pergerakan material.

- UntukEnterprise Automation, dimana perusahaan sudah menerapkan aplikasi ERP (Enterprise Resource Planning) untuk memonitor administrasi pembiayaan produk dan perencanaan.

- UntukFacility Automation, peralatan mesin pabrik masih dominan mekanik dimana operasional mesin hanya untuk produksi, engineer masih berperan penuh terhadap mesin. Perpindahan produk dari mesin ke mesin masih menggunakan tenaga manusia.Instalasi lampu penerangan kurang, perlu diperhatikan.

- UntukShop Floor Conectivity, Monitoring operasional perangkat mesin dilakukan manual dan belum ada dukungan fasilitas komputer yang bisa memantau produksi.

- UntukEnterprise Connectivity, Sistem Operasional perangkat mesin masih bersifat silo (sendiri-sendiri) belum terintegrasi dengan mesin lainnya.

- Untuk Facility Connectivity, secara fungsi mesin produksi buatan eropa (Belgia, Italy) sudah terkoneksi dengan mesin lainnya. Sedangkan untuk mesin produksi dari Cina dan India produksi sendiri.

- Untuk Shop Floor Intelligence; pengoperasian mesin winding, warping, zising, riching, dan weavingmasih menimbulkan kebisingan yang dapat menyebabkangangguan kesehatan dan keselamatan kerja. Tingkat kebisingan perlu dikendalikan untuk menghindari kejadian-kejadian yang dapat mengganggu proses dan kesehatan karyawan. Kebisingan bisa terjadi akibat adanya gesekan pada mesin yang sedang beroperasi, yang 
berpotensi terjadinya kesalahan pekerjaan, kualitas tidak bagus, dan produktivitas rendah.

- UntukEnterprise Intelligence; mulai menginisiasi software ERP untuk memudahkan dalam penjualan,keuangan, manajerial SDM, dan membantu perusahaan dalam mengambil keputusan untuk keperluan analis bisnis

- UntukFacility Intelligence; setiap divisi dilengkapi dengan peralatan komputer

Tabel 1. Penilaian berdasar Aspek Teknologi

\begin{tabular}{|c|c|c|c|c|}
\hline ASPEK & PILAR & DIMENSI & LEVEL & NILAI \\
\hline \multirow{9}{*}{ 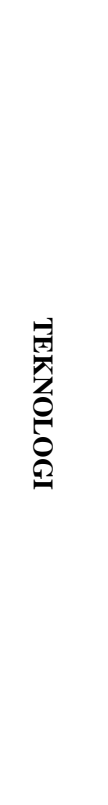 } & \multirow{3}{*}{ 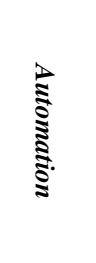 } & $\begin{array}{l}\text { Shop Floor } \\
\text { Automation }\end{array}$ & Basic & 1 \\
\hline & & $\begin{array}{c}\text { Enterprise } \\
\text { Automation }\end{array}$ & Advanced & 2 \\
\hline & & $\begin{array}{c}\text { Facility } \\
\text { Automation }\end{array}$ & Basic & 1 \\
\hline & \multirow{3}{*}{ 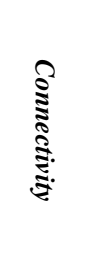 } & $\begin{array}{l}\text { Shop Floor } \\
\text { Connectivity }\end{array}$ & Connected & 1 \\
\hline & & $\begin{array}{c}\text { Enterprise } \\
\text { Connectivity }\end{array}$ & Interopable & 2 \\
\hline & & $\begin{array}{c}\text { Facility } \\
\text { Connectivity }\end{array}$ & Interopable & 2 \\
\hline & \multirow{3}{*}{ 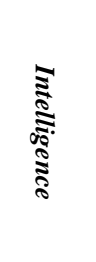 } & $\begin{array}{l}\text { Shop Floor } \\
\text { Intelligence }\end{array}$ & Visible & 2 \\
\hline & & $\begin{array}{l}\text { Enterprise } \\
\text { Intelligence }\end{array}$ & Visible & 2 \\
\hline & & $\begin{array}{c}\text { Facility } \\
\text { Intelligence }\end{array}$ & Computerized & 1 \\
\hline \multicolumn{4}{|c|}{ TOTAL } & 14 \\
\hline \multicolumn{4}{|c|}{ RATA - RATA } & 1.56 \\
\hline
\end{tabular}

\section{- Aspek Proses}

- Belum ada inovasi dalam mengimplementasikan mesin.

- Peningkatan pengalaman pekerjaan dilakukan melalui pelatihan dilakukan secara internal, tapi tidak rutin.

- Ada kemampuan engineer untuk memeriksa perangkat.

- Sudah dibentuk ada Divisi Research and Development, tapi hanya sebatas untuk improved kebutuhan pasar, seperti peluang, trend, harga dan lain - lain belum mengarah pada inovasi produk maupun teknis.

- Keberadaan dokumen ada, tapi tidak tersimpan rapi menjadi satu.

- Adanya Aplikasi Grid Plant berbasis Windows untuk mendukung aktivitas perusahaan terutama melakukan kontrol dalam pembukuan keuangan.

- Ada kebutuhan dari manajemen untuk mendapatkan informasi yang memungkinkan perbaikan dan penggunaan fasilitas.

- Saat ini sedang dikembangkan aplikasi berbasis ERP (Enterprise Resource Planning) untuk mendukung aktivitas perusahaan dalam hal kebutuhan pembukuan keuangan (finance).

- Tidak adanya catatan log book /catatan dokumentasi bila ada kerusakan baik skala kecil.

Tabel 2. Penilaian berdasar Aspek Proses

\begin{tabular}{|c|c|c|c|c|}
\hline ASPEK & PILAR & DIMENSI & LEVEL & NILAI \\
\hline \multirow[t]{3}{*}{$\begin{array}{l}\bar{\pi} \\
\overline{8} \\
\tilde{\Omega}\end{array}$} & 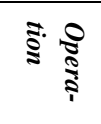 & $\begin{array}{l}\text { Vertical } \\
\text { Integration }\end{array}$ & Defined & 1 \\
\hline & ॠ & $\begin{array}{l}\text { Horizontal } \\
\text { Integration }\end{array}$ & Digital & 2 \\
\hline & 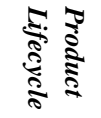 & $\begin{array}{l}\text { Integrated } \\
\text { Product } \\
\text { Lifecycle }\end{array}$ & Defined & 1 \\
\hline \multicolumn{4}{|l|}{ TOTAL } & 4 \\
\hline \multicolumn{4}{|c|}{ RATA - RATA } & $\mathbf{1 . 3 3}$ \\
\hline
\end{tabular}

\section{- Aspek Organisasi}

Organisasi memainkan peran yang sama pentingnya dengan Teknologi dan Proses. Agar tetap relevan dalam menghadapi persaingan yang semakin meningkat di bawah industri 4.0, perusahaan harus menyesuaikan struktur dan proses organisasi mereka untuk memungkinkan perusahaan tetap berjalan.

Telah memiliki jaringan kerjasama yang lebih luas dalam memasarkan produk sendiri dengan siklus produk yg panjang.

- Mampu mengidentifikasi produk dan pasar baru(melalui divisi $\mathrm{RnD}$ ).

Jumlah SDM sebanyak 1700 orang, sebagian besar berketrampilan rendah dan belum memiliki sertifikasi sesuai dengan keahliannya.

- Menerapkan manager baru professional untuk penerapan ERP untuk menangani pembukuan keuangan.

- Dukungan sumber FInansial berasal dari Group (Group Argo).

- Kemampuan manajemen untuk memotivasi karyawan dianggap cukup dengan cara menyisipkan pertemuan dengan motivasi dengan tujuan meningkatkan efisiensi sekaligus menciptakan lingkungan kerja yang kondusif.

Manajemen juga menetapkan disiplin bekerja dengan baik. Hal ini sebagai upaya manajemen untuk tetap menjaga kinerja karyawan.

- Kemampuan perusahaan dalam berkomunikasi dengan supplier sifatnya pasif. Artinya hanya berhubungan pada saat installasi ataupun perbaikan mesin. 
Tabel 3. Penilaian berdasar aspek Organisasi

\begin{tabular}{|c|c|c|c|c|}
\hline ASPEK & $\begin{array}{l}\text { PIL } \\
\text { AR }\end{array}$ & DIMENSI & LEVEL & NILAI \\
\hline \multirow{4}{*}{ 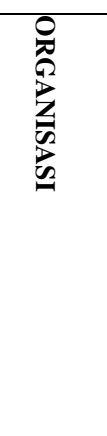 } & \multirow[t]{2}{*}{ 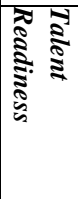 } & $\begin{array}{l}\text { Workforce } \\
\text { Learning \& } \\
\text { Develop-ment }\end{array}$ & $\begin{array}{l}\text { Con- } \\
\text { tinuous }\end{array}$ & 2 \\
\hline & & $\begin{array}{l}\text { Leadership } \\
\text { Competen-cy }\end{array}$ & $\begin{array}{l}\text { Infor- } \\
\text { med }\end{array}$ & 2 \\
\hline & \multirow[t]{2}{*}{ 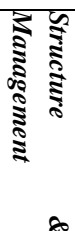 } & $\begin{array}{l}\text { Inter- and } \\
\text { Intra- } \\
\text { Company } \\
\text { Collabora-tion }\end{array}$ & $\begin{array}{l}\text { Coo- } \\
\text { pera-ting }\end{array}$ & 2 \\
\hline & & $\begin{array}{l}\text { Strategy \& } \\
\text { Governance }\end{array}$ & $\begin{array}{l}\text { Develo- } \\
\text { ped }\end{array}$ & 2 \\
\hline \multicolumn{4}{|l|}{ TOTAL } & 8 \\
\hline \multicolumn{4}{|c|}{ RATA - RATA } & 2.00 \\
\hline
\end{tabular}

Untuk mengetahui pemetaan pada masing -masing dimensi, telihat pada gambar 8

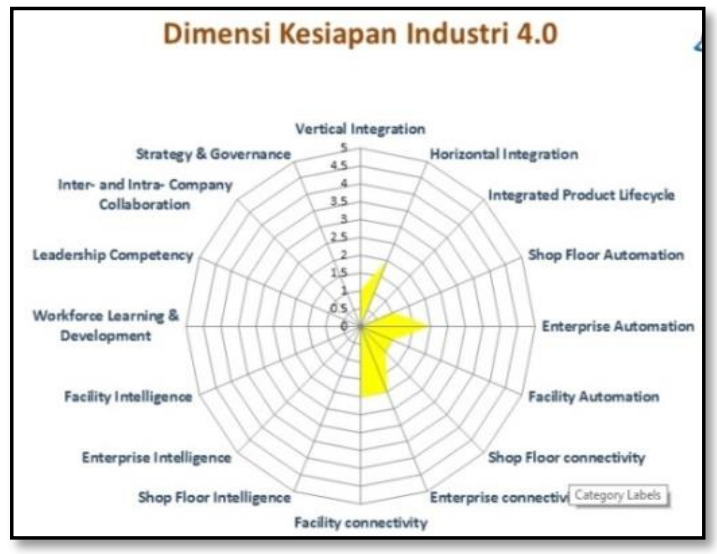

Gambar 4. Diagram radar tentang Kesiapan Industri 4.0

Berdasar gambar 4, menunjukkan bahwa titik puncak level adalah di level 5 , tetapi dar i pengukuran maksimal hanya pada nilai 2 .

Tabel 4. Hasil Pengukuran PT. Grand textile

\begin{tabular}{|c|c|c|c|}
\hline Aspek & Nilai & Posisi & Nilai \\
\hline Teknologi & 1,56 & Level 1 & \multirow{3}{*}{1,63} \\
\hline Proces & 1,33 & Level 1 & \\
\hline Organisasi & 2 & Level 2 & \\
\hline
\end{tabular}

Berdasarkan tabel 4, hasil akumulasi 3 aspek industri 4.0 (Teknologi, Proses, Organisasi), diperoleh rata-rata : 1,63; nilai yang menunjukkan dimana tingkat kesiapan Industri berada pada level 1 (New Comer).

\section{KESIMPULAN}

Berdasar dari hasil penilaian tingkat kesiapan industri 4.0 antara lain sebagai berikut:

1. PT. Grand Textil masih dalam kategori New Comer $(1,63)$, yaitu pada level 0-1. Hasil tesebut diperoleh dari akumulasi penilaian aspek teknologi $(1,56)$, aspek proses $(1,33)$ dan aspek organisasi $(2,00)$.
2. Untuk mencapai tingkat kesiapan "siap" pada industri 4.0, PT.Grand Textile perlu melakukan perubahan perbaikan pada aspek-aspek teknologi (shop floor, enterprise, dan facility dengan semua dimensinya), serta aspek proses (operation, supply chain dan product lifecycle) serta aspek organisasi yang perlu di tingkatkan. Apabila ketiga aspek dipenuhi,maka akan tercipta daya saing industri.

Industri 4.0 menjadi hal yang sangat penting bagi industri Tekstil dan Produk textile (TPT), karena pemanfaatan teknologi dalam industry generasi keempat dapat mempermudah pekerjaan bukan menggantikan fungsi pekerja manusia dengan robot. Untuk dapat berperan dalam industri 4.0 selayaknya mengedepankan teknologi modern agar lebih efisien serta ditunjang dengan peningkatan kompetensi SDM sesuai kebutuhan di era digital. Ketersediaan teknologi modern berupa mesin potong, mesin border, mesin obras, mesin jahit dan teknologi desain serta dukungan teknologi informasi (TI) dalam model dan desain dianggap penting dan merupakan merupakan peluang dalam pengembangan industri produk tekstil menuju level industri 4.0.Untuk memperkuat pelaku industri tekstil diperlukan peningkatan kapasitas melalui investasi mesin modern dengan skema pembiayaan ramah industri.

Untuk dapat mencapai level industri 4.0, sebaiknya diawali dengan masa transisi dimana tidak harus penerapan $100 \%$ teknologi baru.Disesuaikan dengan anggaran dan kondisi perusahaan.Terpenting adalah kesiapan kompetensi dari SDM agar dapat meningkatkan daya saing industry menuju level industry 4.0.

Telah tiba waktunya bagi Indonesia untuk melakukan perubahan menyeluruh terhadap sektor manufakturnya untuk berevolusi memperoleh manfaat penuh dalam Industri 4.0, di mana sistem komputasi terintegrasi dan jaringan dan proses fisik merevolusi industri manufaktur.

\section{REFERENSI}

[1] Badan Pusat Statistik (BPS).(2018). Pertumbuhan Produksi Industri Manufaktur Triwulan III 2018 No. 88/11/Th. XXI, 01 November 2018

[2] Economic Development Board (EDB) Singapore.(2017). The Singapore Smart Industry Readiness Index : Catalysing the Transformation of Manufacturing. Singapore : Singapore Economic Development Board.

[3] Hermann, M., Pentek, T., \& Otto, B. (2016). Design Principles for Industrie 4.0 Scenarios. Presented at the 49th Hawaiian International Conference on Systems Science.

[4] Irianto, D. (2017). Industry 4.0; The Challenges of Tomorrow. Disampaikan pada Seminar Nasional Teknik Industri-Malang.

[5] Kemenperin. 2018. Making Indonesia 4.0. Disampaikan oleh Menteri Perindustrian pada acara 
Launching Making Indonesia 4.0 , tanggal 4 April 2018

[6] Kemenperin. 2018. Hadapi Era Digital kemenperin Fokus Prioritaskan Lima Sektor Industri. Siaran Pers.(http://www.kemenperin.go.id/artikel/18993/Had api-Era-Digital,-Kemenperin-Fokus-PrioritaskanLima-Sektor-Industri, diakses 10 Februari 2019).

[7] Muhammad Yahya.(2018).Era Industri 4.0: Tantangan Dan Peluang Perkembangan Pendidikan Kejuruan Indonesia . Disampaikan pada Sidang Terbuka Luar Biasa Senat Universitas Negeri Makassar Tanggal 14 Maret 2018

[8] Riyardi, Agung, dkk. (2015). Analisis Pertumbuhan Industri Tekstil dan Produk Tekstil di berbagai provinsi di Pulau Jawa. Univesity Research Colloquium 2015.

[9] Sahat, Siska, F. 2016. Tekstil dan Produk Tekstil. Warta Ekspor, Ditjen PEN/MJL/19/IV/2016 edisi April 2016: 4 .

[10] Tjandrawina, R.R. (2016). Industri 4.0: Revolusi industri abad ini dan pengaruhnya pada bidang kesehatan dan bioteknologi. Working Paper from Dexa Medica Group. 2 February 2016.

[11] Unido. (2017). Industry 4.0 Opportunities Behind The Challenge Background Paper. Vienna : Unido General Conference 17, 27 November - 1 Desember 2017. 